Article

\title{
Immobilization of Lipases on Magnetic Collagen Fibers and Its Applications for Short-Chain Ester Synthesis
}

\author{
Shengsheng $\mathrm{He}^{1}$, Dewei Song ${ }^{1}$, Min Chen ${ }^{1,2}$ and Haiming Cheng ${ }^{1,2, *}$ \\ 1 The Key Laboratory of Leather Chemistry and Engineering of Ministry of Education, Sichuan University, \\ Chengdu 610065, China; 2015223085064@stu.scu.edu.cn (S.H.); 2013223080019@stu.scu.edu.cn (D.S.); \\ cm_qfxy@scu.edu.cn (M.C.) \\ 2 National Engineering Laboratory for Clean Technology of Leather Manufacture, Sichuan University, \\ Chengdu 610065, China \\ * Correspondence: chenghaiming@scu.edu.cn; Tel.: +86-288-540-5839
}

Academic Editor: David D. Boehr

Received: 5 April 2017; Accepted: 16 May 2017; Published: 7 June 2017

\begin{abstract}
Magnetic nanoparticles $(\mathrm{MNp}) \mathrm{Fe}_{3} \mathrm{O}_{4}$ were prepared by chemical coprecipitation, and introduced onto collagen fibers to form magnetic collagen support ( $\mathrm{MNp}$-Col) for enzyme immobilization. Candida rugosa lipase has been successfully immobilized on $\mathrm{MNp}$-Col supports by a covalent bond cross-linking agent, glutaraldehyde. The characteristics of $\mathrm{MNp}-\mathrm{Col}$ and the immobilized lipase were investigated. The immobilized lipase displayed sound magnetic separation abilities in both aqueous and organic media. The activity of the immobilized lipase reached $2390 \mathrm{U} / \mathrm{g}$ under optimal conditions. The $\mathrm{MNp}-\mathrm{Col}$ immobilized lipase shows broadened temperature and $\mathrm{pH}$ ranges for hydrolysis of olive oil emulsion. For synthesis of butyrate esters in an n-hexane medium, the yield changes through use of different alcohols, among which, butyric butyrate showed the highest yield. The prepared magnetic collagen fiber provides separation support for enzyme immobilization and has the potential to be used in other biotechnology fields.
\end{abstract}

Keywords: lipase; magnetic particle; immobilization; collagen; butyrate

\section{Introduction}

Enzymes are broadly used as 'green' biocatalysts in many fields because enzymatic reactions are normally carried out at mild conditions with high efficiency and specificity [1]. However, several shortcomings such as high cost, unstability to thermal or chemical, and non-reusability have restricted the application of free enzymes [2-4]. Enzyme immobilization has been reported as a valuable alternative since it not only permits the reuse of enzymes, but also improves some other critical properties like activity, inhibition by reaction products, and selectivity [5].

Lipases are the biocatalysts that can catalyze reactions including acetylation, hydrolysis (of triacylglycerols), alcoholysis, esterification, transesterification, and interesterfication [6-8]. The performances of immobilized lipases rely on the immobilization techniques and the chemical property of the support as well [6]. Lipases have been immobilized by numerous methods such as covalent bonding, cross-linking, entrapment, encapsulation, and adsorption [9,10]. Different natural polymers have been employed for lipase immobilization such as agarose, alginate, chitosan, cellulose, and starch $[11,12]$.

Collagen fibers are bioresources that are inexpensive and readily available in animal skins and bones. Made up of spongy characteristics and the existence of functional groups such as carboxyl, amino, and hydroxyl groups, collagen fibers have been proposed by many as supports for enzyme immobilization [13-15]. In our previously study, collagen fibers were developed as supports for 
immobilizing lipase, and the immobilized lipase (Col-GA-IL) showed positive activity for butyl butyrate synthesis [15].

Magnetic nanoparticles (MNPs) have been reported for lipase immobilization [16-18]. Magnetite $\left(\mathrm{Fe}_{3} \mathrm{O}_{4}\right)$ is one of the iron oxides used most often. The magnetic supports are beneficial to be separated from the reaction media by using an external magnet. Furthermore, the immobilized enzyme on the magnetic nanoparticles may show higher retention of enzyme activity, storage, and operational stability [17]. Herein, the $\mathrm{Fe}_{3} \mathrm{O}_{4}$ magnetic nanoparticles coated with oleic acid were prepared and then mixed with bovine skin collagen fibers as the support ( $\mathrm{MNp}-\mathrm{Col})$ for lipase immobilization. Glutaraldehyde (GA) was used as a cross-linking agent. The characteristics of the obtained immobilized lipase on $\mathrm{MNp}$-Col were determined and the application of it as biocatalysts for short chain ester synthesis was investigated. This work showed that $\mathrm{Fe}_{3} \mathrm{O}_{4}$ collagen immobilized lipases (MNp-Col-IL) maintain high activity and specificity for butyrate synthesis in an $\mathrm{n}$-hexane medium.

\section{Results and Discussion}

\subsection{Characterization}

The results of $\mathrm{N}_{2}$ adsorption-desorption of native collagen fiber, $\mathrm{MNp}$-Col supports, and MNp-Col-IL are shown in Table 1. The total pore volume and Brunauer, Emmett, Teller (BET) surface area of native collagen fiber were only $0.0049 \mathrm{~m}^{3} / \mathrm{g}$ and $2.10 \mathrm{~m}^{2} / \mathrm{g}$, respectively. This is relatively low compared with other porous supports [19-21]. However, after grafting with $\mathrm{Fe}_{3} \mathrm{O}_{4}$ particles, the BET surface area of MNp-Col is $11.59 \mathrm{~m}^{2} / \mathrm{g}$, nearly 5.5 times bigger than native collagen. While immobilized by lipase, the BET surface area of the support shifted to $7.63 \mathrm{~m}^{2} / \mathrm{g}$, which is still 3.6 times bigger than native collagen. The total pore volume of MNp-Col supports is $0.042 \mathrm{~m}^{3} / \mathrm{g}$, which is approximately 10 times bigger than native collagen. After immobilization, the total pore volume was maintained at $0.038 \mathrm{~m}^{3} / \mathrm{g}$. This indicates that the introduction of $\mathrm{Fe}_{3} \mathrm{O}_{4}$ particles led to an increase of pore volume and a rougher surface of collagen fiber, while the immobilizing of lipase onto the magnetic supports caused a slight decrease of pore volume. The average pore sizes of native collagen, $\mathrm{MNp}-\mathrm{Col}$ and MNp-Col-IL, are approximately 13.70, 10.47, and $14.65 \mathrm{~nm}$, respectively. This shows that the pores in collagen fiber supports and MNp-Col-IL fall into the mesopore size range [21]. The average pore size of native collagen decrease when magnetic particles are added, and then increases again upon lipase immobilization. This should be due to GA used for cross-linking the enzyme.

Table 1. The pore size of magnetic collagen support and immobilized lipase.

\begin{tabular}{cccc}
\hline Samples & BET Surface Area $\left(\mathrm{m}^{\mathbf{2}} / \mathbf{g}\right)$ & Average Pore Size $(\mathbf{n m})$ & Pore Volume $\left(\mathrm{cm}^{\mathbf{3}} / \mathbf{g}\right)$ \\
\hline Native collagen [15] & 2.10 & 13.7 & 0.0049 \\
MNp-Col support & 11.59 & 10.47 & 0.042 \\
MNp-Col-IL & 7.63 & 14.65 & 0.038 \\
\hline
\end{tabular}

SEM images of MNp-Col-IL are shown in Figure 1. The magnetic particles were dispersed uniformly on the surface of collagen fiber. The physical adsorption may be the main cause in stabilizing the magnetic nanoparticles onto the collagen fiber. The surface of MNp-Col-IL appeared to be of irregular morphology, and layers of $\mathrm{Fe}_{3} \mathrm{O}_{4}$ particles could be observed. It demonstrated that $\mathrm{Fe}_{3} \mathrm{O}_{4}$ composite particles play a significant role in the enlargement of the surface area of MNp-Col and MNp-Col-IL. 


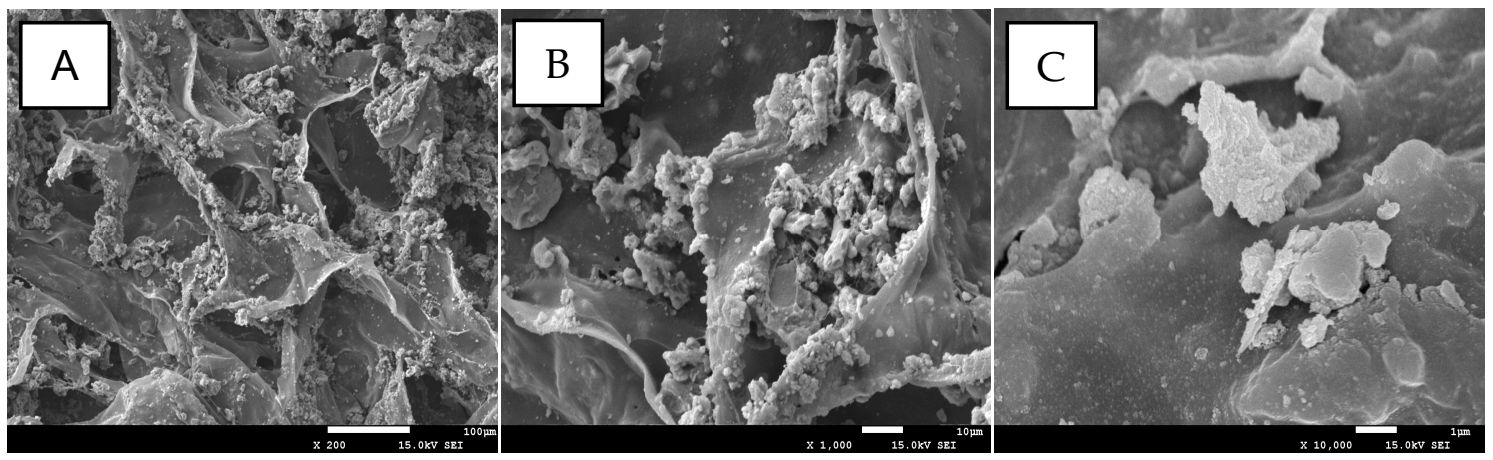

Figure 1. SEM profiles of MNp-Col-IL in different resolutions. $(\mathbf{A}) \times 200,(\mathbf{B}) \times 1000$, and $(\mathbf{C}) \times 10,000$.

$\mathrm{MNp}$-Col-IL showed positive dispersion ability in both aqueous and organic media, especially in aqueous (Figure 2). On the other hand, it could be separated from the medium within $10 \mathrm{~s}$ by an imposed magnetic field. This illustrates that the prepared magnetic collagen could be a potential support for enzyme immobilization that can be easily separated from the reaction medium.
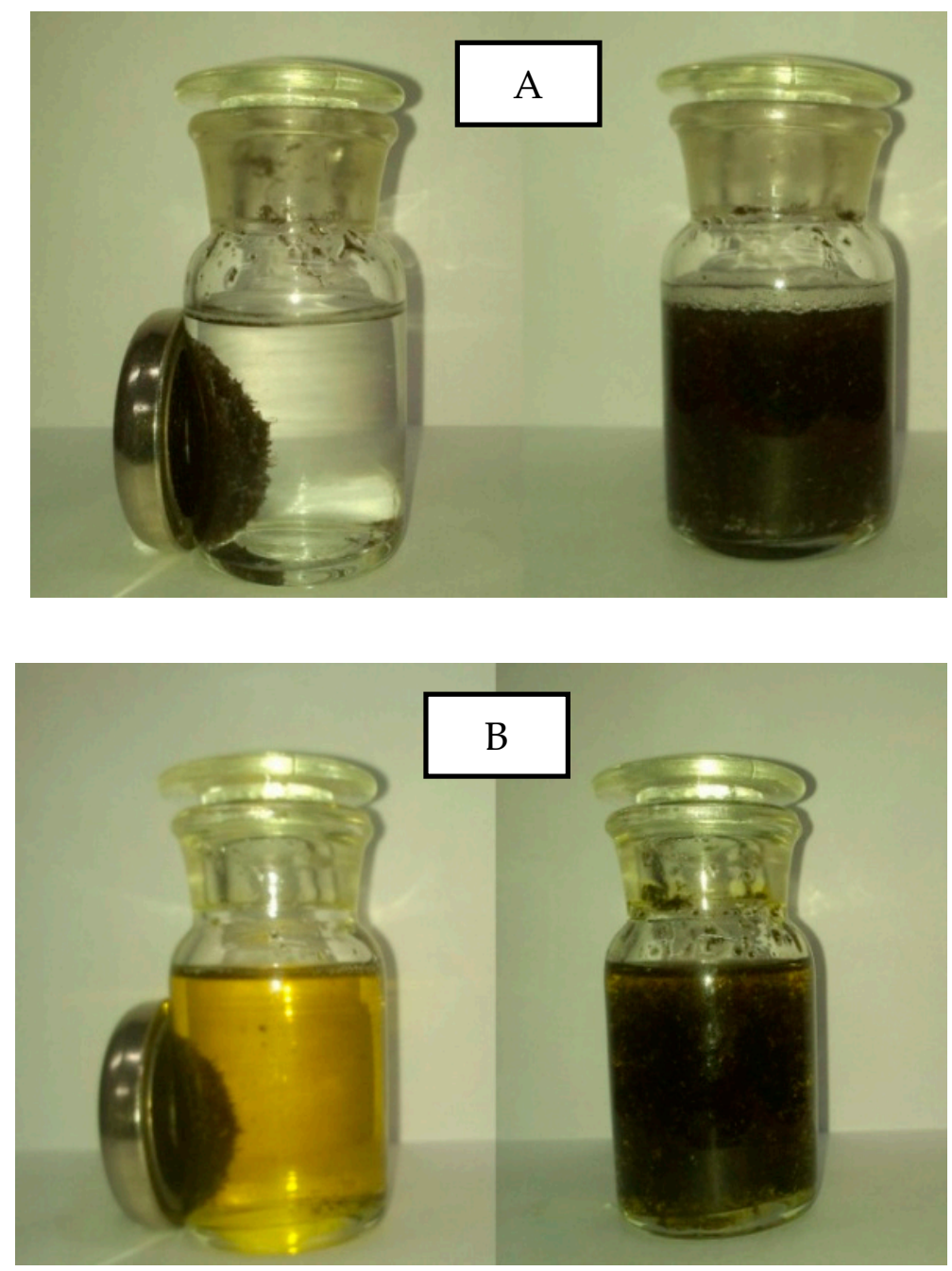

Figure 2. Pictures of the dispersion and magnetic separation effect of MNp-Col-IL in media. (A) aqueous, and (B) olive oil. 
The denaturation temperature (Td) of the $\mathrm{MNp}-\mathrm{Col}$ supports and immobilized lipase was investigated by differential scanning calorimeter (DSC) (Figure 3A). The Td of native collagen fiber is $57.9^{\circ} \mathrm{C}$, while the $\mathrm{Td}$ of $\mathrm{MNp}$-Col and MNp-Col-IL were observed at $69.9^{\circ} \mathrm{C}$ and $69.2^{\circ} \mathrm{C}$, respectively. This is an increase of approximately $12{ }^{\circ} \mathrm{C}$ compared to the native collagen. Glutaraldehyde (GA), the widely used cross-linking agent for collagen fibers, could improve the thermal stability of collagen fibers due to the forming of chemically stable covalent bonds between the side chain amino groups of the residues by formation of Schiff bases [22]. The enhancement of Td by GA implies a broader processing temperature range of the magnetic collagen support, which is beneficial to enzyme immobilization.
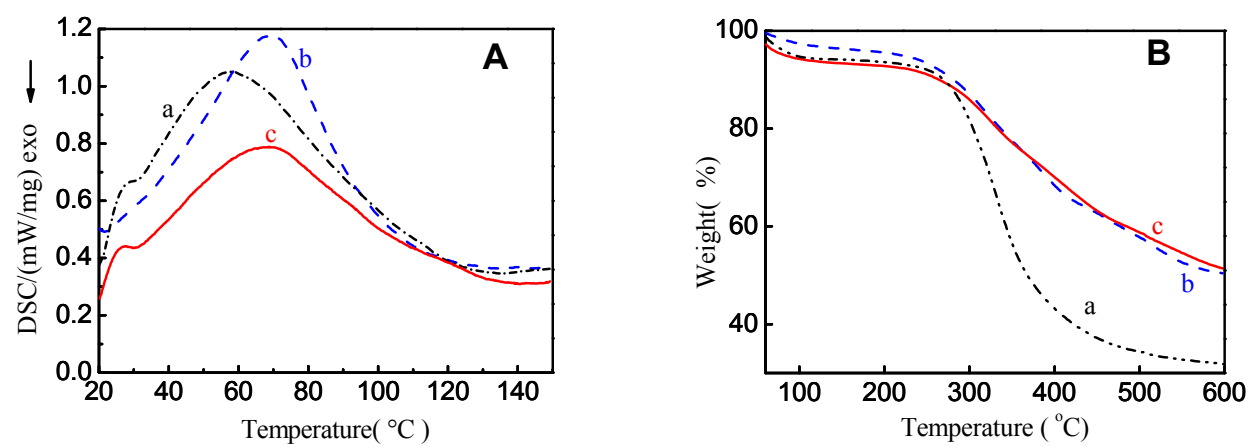

Figure 3. DSC (A) and TG (B) profiles. (a) Collagen Fiber, (b) MNp-Col support, and (c) MNp-Col-IL.

The thermogravimetry (TG) profiles showed that the major decomposition temperature for native collagen fiber was from 280 to $400{ }^{\circ} \mathrm{C}$, and the major weight loss was $65 \%$. The major decomposition temperature for $\mathrm{MNp}$-Col and MNp-Col-IL was from 300 to $500{ }^{\circ} \mathrm{C}$, and the major weight loss was only $37 \%$ (Figure 3B). This may be due to the dilution effect of $\mathrm{Fe}_{3} \mathrm{O}_{4}$ particles. The improvement of the heat decomposition resistance of $\mathrm{MNp}-\mathrm{Col}$ and $\mathrm{MNp}$-Col-IL can be contributed to the cross-linking by GA [23].

\subsection{The Effects on Immobilization Process}

\subsubsection{Initial Concentration of Lipase Solution}

The immobilization of C. rugosa lipase onto MNp-Col support was performed at $20{ }^{\circ} \mathrm{C}$ and $\mathrm{pH} 7.5$ for six hours by varying the initial concentration of lipase from 5 milligrams/milliliter to $50 \mathrm{mg} / \mathrm{mL}$. The results were shown in Figure $4 \mathrm{~A}$. The activity of MNp-Col-IL increases as the initial concentration rises $5-30 \mathrm{mg} / \mathrm{mL}$, and reaches a peak value $2390 \mathrm{U} / \mathrm{g}$ at $30 \mathrm{mg} / \mathrm{mL}$, in which $70.4 \%$ of the expressed activity (observed activity/expected activity considering immobilized enzyme) was recovered. The results showed that the activity of lipase decreased at too high or too low enzyme concentration. The immobilization reaction occurs by covalent bonds between free aldehyde groups on the support and primary amino groups on the side chain of lipase [22,23]. When lipase concentrations were higher than $30 \mathrm{mg} / \mathrm{mL}$, the observed activity of MNp-Col-IL was lower, indicating that excessive immobilized enzymes on the support could hamper their transformation into active conformations for catalysis of the hydrolysis reaction. Similar results were observed by others [21,24]. Furthermore, the immobilization procedure may cause secondary structural changes to the enzyme molecules, especially when some multipoint covalent bonds are built between the support and the enzyme [25]. 

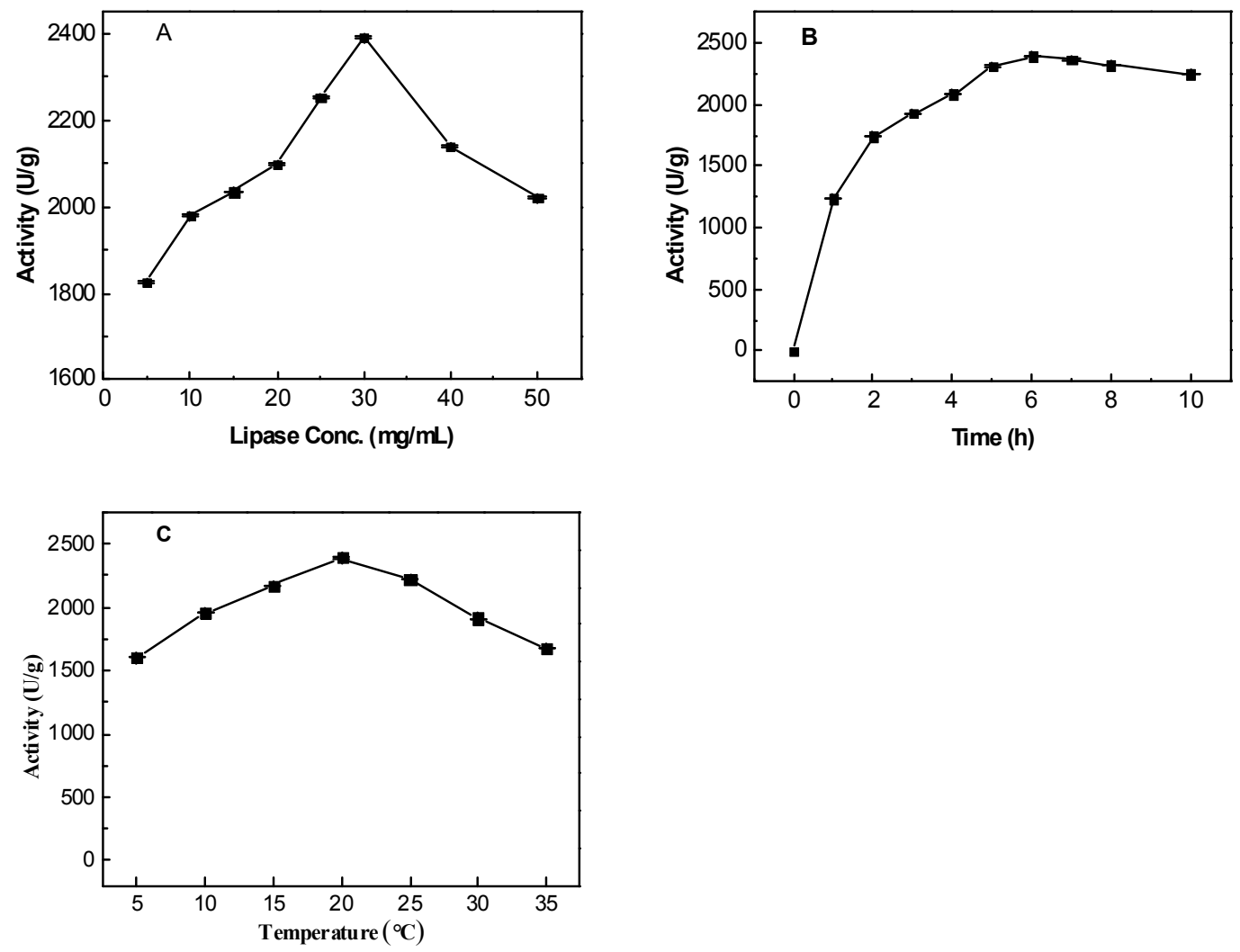

Figure 4. Effect of the parameters on the lipase immobilization. (A) lipase concentration, (B) time, and (C) temperature.

\subsubsection{Incubation Time}

The effect of incubation time was investigated at $\mathrm{pH} 7.5$ and $20^{\circ} \mathrm{C}$ with the initial concentration of lipase at $30 \mathrm{mg} / \mathrm{mL}$ by varying incubation duration from 1 hour to $10 \mathrm{~h}$. The results were shown in Figure 4B. The activity of MNp-Col-IL increased gradually in the first six hours, exhibited maximal activity at six hours, and the observed activity remained stable afterwards.

\subsubsection{Temperature}

The immobilization processes were operated with the initial concentration of lipase at $30 \mathrm{mg} / \mathrm{mL}$ at temperatures varying from 5 to $35{ }^{\circ} \mathrm{C}$. The activities of MNp-Col-IL were determined and the results were shown in Figure $4 \mathrm{C}$. The optimal immobilization temperature was $20^{\circ} \mathrm{C}$. The activity decreases noticeably once the process temperature rises above $20^{\circ} \mathrm{C}$. This result may indicate that the conformation of the enzyme may be loosened at a high temperature, and the cross-linking reaction during immobilization will hinder the right conformation [26].

\subsection{Operational Activity of Immobilized Lipase}

\subsubsection{Temperature}

The mixture of free lipase or MNp-Col-IL with substrate emulsion ( $\mathrm{pH}$ 8.0) was incubated at temperatures varying from 15 to $70{ }^{\circ} \mathrm{C}$. The activities were measured periodically. The results are shown in Figure 5A. 

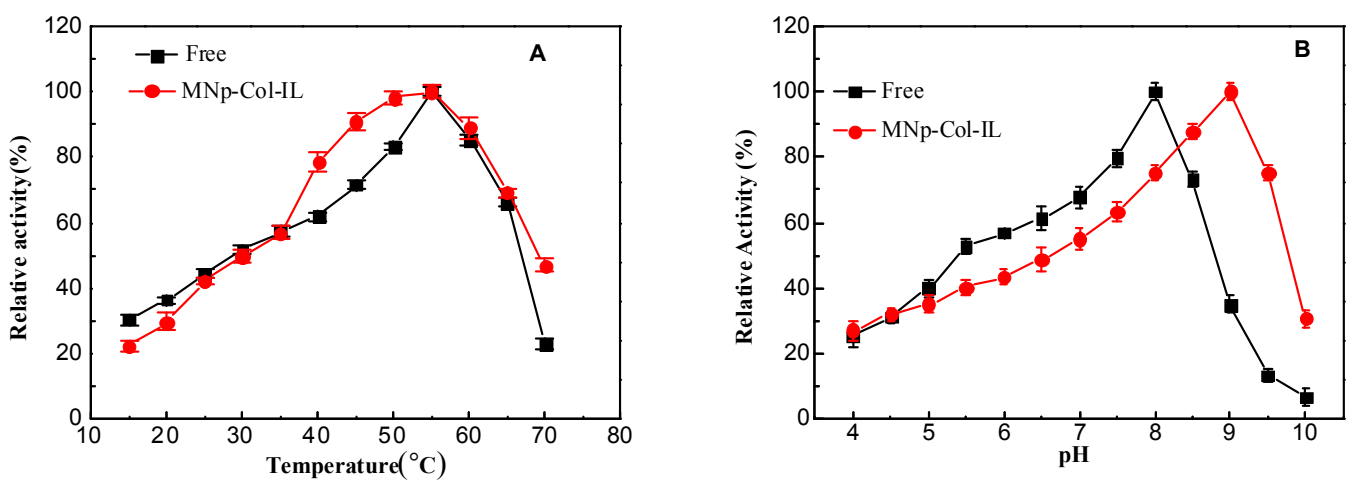

Figure 5. Effect of Temperature and $\mathrm{pH}$ on the relative activity. (A) temperature, and (B) $\mathrm{pH}$.

The optimal activity for both free lipase and MNp-Col-IL are at $55^{\circ} \mathrm{C}$ (Figure 5A). However, $\mathrm{MNp}$-Col-IL maintains high activity at a broader range of temperature than the free lipase. Between $40{ }^{\circ} \mathrm{C}$ and $65{ }^{\circ} \mathrm{C}$, more than $90 \%$ of the relative activity could be maintained. At $70{ }^{\circ} \mathrm{C}$, the maintained relative activity for MNp-Col-IL is three times higher than that of the free lipase. The multi-interactions between the support and lipase may play a vital role in the tolerance to temperature of immobilized lipase.

\subsubsection{Effect of $\mathrm{pH}$}

Olive oil emulsion was used as a substrate to investigate the effect of $\mathrm{pH}$ on the activity of free lipase and MNp-Col-IL by varying the $\mathrm{pH}$ range from 4.0 to 9.5. The optimal $\mathrm{pH}$ of MNp-Col-IL is 9.0 (Figure 5B), which is one unit higher compared to free enzyme (optimal pH 8.0). Interestingly, $\mathrm{MNp}-\mathrm{Col}-\mathrm{IL}$ shows a broadened $\mathrm{pH}$ range compared to the free lipase. Such a change and widening of the optimal $\mathrm{pH}$ value may be caused by diffusion resistance to the fatty acid in the hydrolyzed emulsion transport on the surface of the support [27]. The stabilization of MNp-Col-IL by covalent bonding on the support may limit the active conformation of lipase against the $\mathrm{pH}$ change of the medium [28].

\subsubsection{The Kinetic Parameters}

The kinetic parameters of $K_{\mathrm{m}}$ and $V_{\max }$ are commonly used to evaluate the catalytic efficiency of immobilized verses of free enzymes. The kinetic parameters, $K_{m}$ and $V_{\max }$, of free and immobilized enzymes were evaluated by Lineweaver-Burk plot (Figure 6). The $K_{m}$ value of the free lipase and MNp-Col-IL is at $27.54 \mathrm{mM}$ and $36.11 \mathrm{mM}$ respectively (Table 2). The $K_{m}$ of MNp-Col-IL is higher than that of the free lipase, suggesting that the immobilized lipase acting at half of maximum velocity needs a higher concentration of substrate. Furthermore, MNp-Col-IL has weaker affinity than free lipases [29]. Such a decrease in affinity is apparent, which may due to the mass transfer limitations that result of immobilization. Lower $K_{m}$ value decreases of the MNp-Col-IL compared with Col-GA-IL ( $56.68 \mathrm{mM}$ ) may be due to the introduction of $\mathrm{Fe}_{3} \mathrm{O}_{4}$ particles. This enhanced the hydrophobicity of immobilized enzymes and improved the binding efficiency of substrate. The $V_{\max }$ value of MNp-Col-IL was $38.5 \%$ that of free lipase. The decrease in $V_{\max }$ might be due to generous secondary conformational perturbation, and changes on the lipase surface upon immobilization. The catalytic efficiency $\left(V_{\max } / K_{\mathrm{m}}\right)$ of MNp-Col-IL (0.11) is lower than that of free lipase (0.37), illustrating that MNp-Col-IL has a relatively low catalytic efficiency $[30,31]$. 


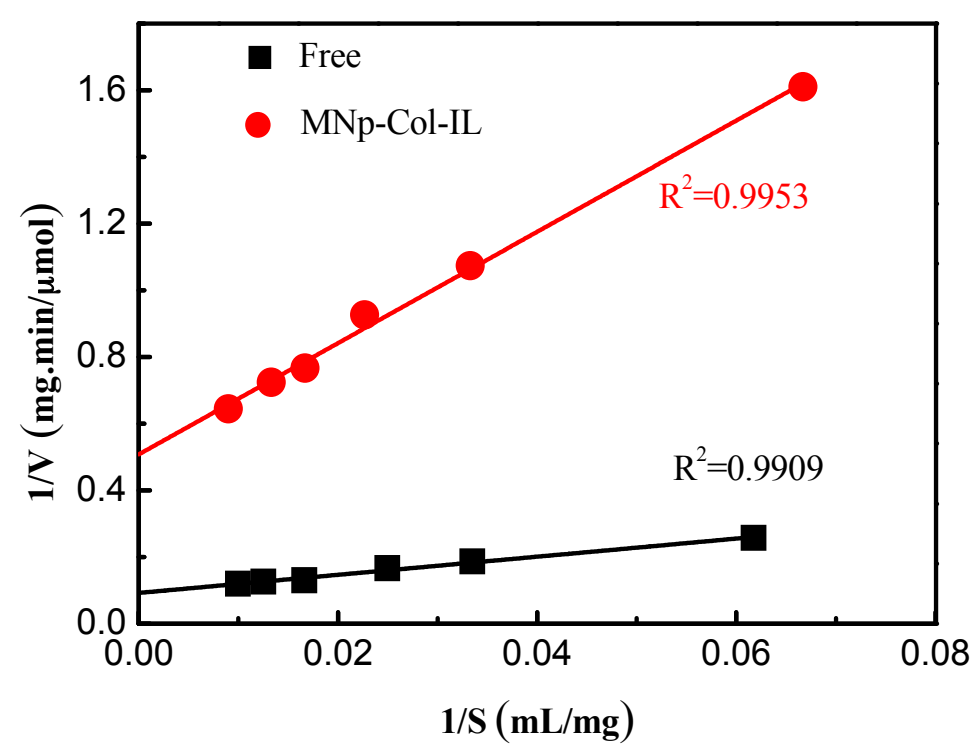

Figure 6. Lineweaver-Burk plots of free lipase and MNp-Col-IL.

Table 2. The kinetic parameters.

\begin{tabular}{ccccc}
\hline Lipase & $K_{\mathbf{m}}(\mathbf{m M})$ & $V_{\max }(\mathbf{m M} / \mathbf{m i n})$ & $V_{\max } / K_{\mathbf{m}}$ & Relative Activity (\%) \\
\hline Free & 27.54 & 10.25 & 0.37 & 100 \\
MNp-Col-IL & 36.11 & 3.97 & 0.11 & 30 \\
\hline
\end{tabular}

\subsubsection{Storage Stability and Reusability Examinations}

The storage stability of immobilized enzymes is an essential aspect for their industrial applications. In the storage stability study, MNp-Col-IL and free lipases were stored at $4{ }^{\circ} \mathrm{C}$ and their activity was determined at five day intervals. The activity of free lipase decreased to $60 \%$ of the initial activity after only five days, while the immobilized lipase reached the same loss of activity after 25 days (Figure 7). At 30 days of storage, MNp-Col-IL still preserved $50 \%$ of the initial activity compared to only $8 \%$ for free lipases. This suggests that MNp-Col-IL has significantly better storage stability than the free lipase. The significant loss of activity for the free lipase during storage might be due to its higher susceptibility to autolysis. A similar result was reported in the immobilization of C. rugosa lipase after being stored 30 days at $4{ }^{\circ} \mathrm{C}$ while the free lipase retained only $10 \%$ of its initial activity [20].

For immobilized enzymes, reusability is another character. The used MNp-Col-IL was recovered and used again for a hydrolytic activity test. As shown in Figure 8 , at least $75 \%$ of the initial activity kept after MNp-Col-IL was reused for 10 cycles. A small loss of activity during the recovery/reuse cycles is possibly since the conformation of lipase was influenced by organic solvent [32,33]. This result demonstrates that $\mathrm{MNp}-\mathrm{Col}$ has a positive potential for lipase immobilization and related bio-catalytic applications. 


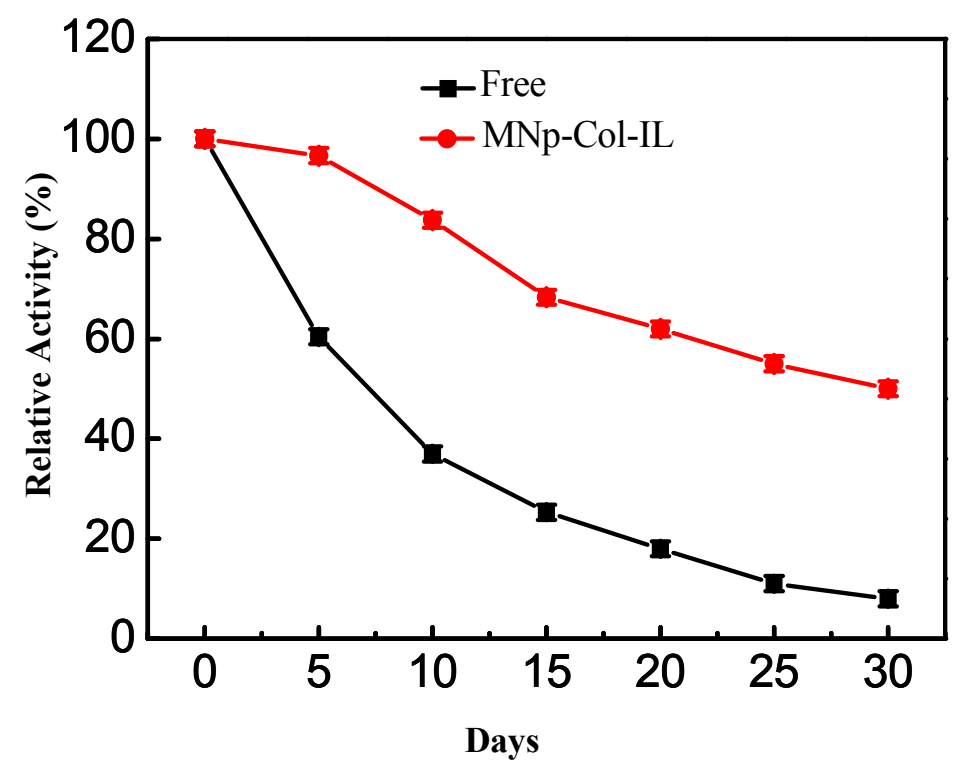

Figure 7. Storage stability of free and immobilized lipase.

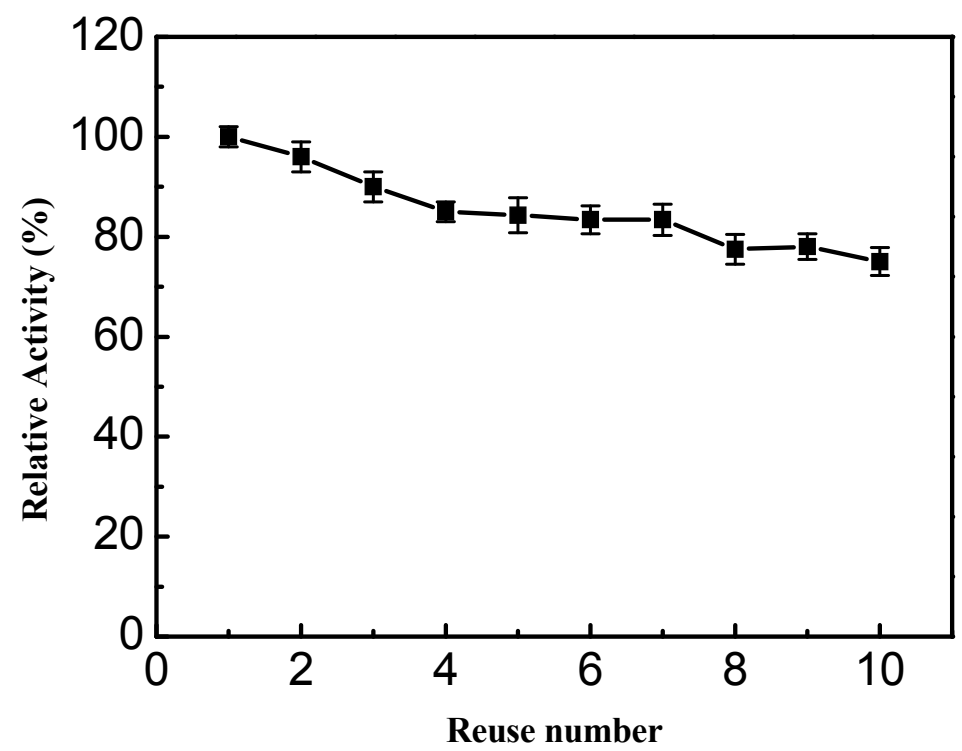

Figure 8. Reusability potential of MNp-Col immobilized lipase for hydrolysis of olive oil emulsion.

\subsection{Synthesis of Butyrate by MNp-Col-IL}

Short chain esters are a kind of important flavoring and fragrance agents [34-36]. Lipases are often used as the catalyst of choice because the reactions can be carried out at mild temperatures, and the processes using these catalysts are considered clean. The MNp-Col-IL catalyzed synthesis of butyric acid esters was investigated.

Table 3 shows the yields for the synthesis of various esters. It showed that MNp-Col-IL effectively catalyzed the synthesis of several short-chain flavoring esters. The yield of butyl butyrate was observed with a peak value of $82.7 \%$. While other butyrate esters displayed less yield, such as the yield of methyl butyrate and n-hexyl butyrate observed at $39.8 \%$ and $36.2 \%$, respectively. The alcohol length and position of the hydroxyl groups have important effects on the yields [34,35]. During the esterification process, a tetrahedral complex will be formed between the enzyme and acid by losing water, and then the alcohol binds to the acyl enzyme intermediate, acting as a nucleophile, thus forming a second 
tetrahedral complex. Resolution of this tetrahedral complex yields the ester and the free enzyme [36]. Therefore, the diffusion rate of the alcohol to the active site should play a key role to the reaction.

Table 3. The yield of butyrate synthesis catalyzed by MNp-Col-IL.

\begin{tabular}{cccc}
\hline Alcohol & Yield (\%) & Alcohol & Yield (\%) \\
\hline Methanol & 39.8 & Iso-butanol & 61.9 \\
Ethanol & 44.5 & Tert-butanol & 6.2 \\
N-propanol & 56.1 & N-amyl alcohol & 63.4 \\
Iso-propanol & 22.3 & Iso-amyl alcohol & 49.1 \\
N-butanol & 82.7 & N-hexyl alcohol & 36.2 \\
\hline
\end{tabular}

The efficiency and specificity of lipase catalyzed esterification is governed by the chain length of acids and alcohols [37]. Shinetre et al. [38] reported that the initial rate of reaction increases linearly with increasing the chain length of fatty acid. Interestingly, Table 3 also showed that different alcohol isomers exhibited different yields, with the following order: $n$-alcohol $>$ iso-alcohol $>$ tert-alcohol. This could be explained by the influence of steric effects [36,39]. The conversion of iso-butanol $(61.9 \%)$ and tert-butanol $(6.2 \%)$ was significantly lower compared with n-butanol $(82.7 \%)$. This is probably due to progressively higher steric hindrance by the methyl groups in the proximity of the hydroxyl group. Results consistent with our work have been observed in previous studies focusing on the effects of the structures of alcohols on ester synthesis catalyzed by lipases [39-41]. In general, $\mathrm{Fe}_{3} \mathrm{O}_{4}$-collagen immoblilzed lipases displayed high activity and specificity for butyrate synthesis in an n-hexane medium.

\section{Materials and Methods}

\subsection{Materials}

Bovine collagen fibers were prepared based on established methods described elsewhere [42]. Candida rugosa lipase (E.C. 3.1.1.3) (10,000 U/g) was donated by Leveking Bio-Engineering (Leveking Bio-Engineering, Shenzhen, China). Ferric chloride hexahydrate, ferrous chloride tetrahydrate, glutaraldehyde $(45 \%, v / v)$, butyric acid, various alcohols, and other reagents were of analytical grade. The deionized water (18.2 M $\Omega$ ) was used for the preparation of buffers.

\subsection{Preparation of Magnetic $\mathrm{Fe}_{3} \mathrm{O}_{4}$ Particles}

Preparation of $\mathrm{Fe}_{3} \mathrm{O}_{4}$ magnetic particles was carried out according to the chemical coprecipitation method reported by others [16]. Briefly, $5.4 \mathrm{~g}$ of $\mathrm{FeCl}_{3} \cdot 6 \mathrm{H}_{2} \mathrm{O}$ and $2.0 \mathrm{~g}$ of $\mathrm{FeCl}_{2} \cdot 4 \mathrm{H}_{2} \mathrm{O}$ were dissolved together in $100 \mathrm{~mL}$ water at $25^{\circ} \mathrm{C}$ with vigorous stirring. Then $20 \%$ of $\mathrm{NH}_{3} \cdot \mathrm{H}_{2} \mathrm{O}$ was added to adjust the $\mathrm{pH}$ value to 10 with vigorous stirring. The formed particles were black, and exhibited a strong response to an imposed magnetic field $1.0 \mathrm{~mL}$ of oleic acid was added and the mixture was incubated at $60^{\circ} \mathrm{C}$ for $30 \mathrm{~min}$. The synthesized $\mathrm{Fe}_{3} \mathrm{O}_{4}$ were then filtered, rinsed, with deionized water and ethanol for several times, and used directly for the preparation of magnetic collagen support (MNp-Col).

\subsection{Preparation of Magnetic Collagen Support and Enzyme Immobilization}

The magnetic collagen supports were prepared by mixing $\mathrm{Fe}_{3} \mathrm{O}_{4}$ magnetic particles with collagen fiber dispersion. Briefly, $5.0 \mathrm{~g}$ of collagen fiber and $100 \mathrm{mg} \mathrm{Fe}_{3} \mathrm{O}_{4}$ magnetic particles were dispersed in $10 \mathrm{~mL}$ of $0.1 \mathrm{M}$ acetic acid (HAc) with vigorous stirring. Subsequently, $10 \mathrm{~mL}$ of $45 \%$ glutaraldehyde was added for covalent bonding. The mixture was stirred for one hour at $30^{\circ} \mathrm{C}$ before the $\mathrm{pH}$ value was adjusted to 7.5 by $0.1 \mathrm{M}$ sodium bicarbonate and the mixture incubated for another hour. The obtained magnetic collagen supports ( $\mathrm{MNp}-\mathrm{Col}$ ) were separated by an imposed magnetic field, and thoroughly rinsed with deionized water. 
To immobilize lipase onto the functionalized MNp-Col support by covalent bonding, $2.5 \mathrm{~g}$ of the prepared MNp-Col support was added into $100 \mathrm{~mL}$ of $5-50 \mathrm{mg} / \mathrm{mL}$ lipase solution (50 mM PBS buffer, $\mathrm{pH}$ 7.5) with vigorous stirring at $5-35{ }^{\circ} \mathrm{C}$. After a set duration of reaction time, the solids were separated by magnetic field and washed with $50 \mathrm{mM}$ PBS buffer (pH 7.5) and deionized water thoroughly to remove the excess free lipase. The obtained immobilized lipase on the magnetic collagen support (MNp-Col-IL) was then stored at $4{ }^{\circ} \mathrm{C}$, and lyophilized for further use.

\subsection{Hydrolytic Activity Assays}

The hydrolytic activities of both free lipase and MNp-Col-IL were determined according to a reported colorimetric assay and described elsewhere [15,43]. One unit (U) of enzyme activity was defined as the amount of enzyme which liberated one $\mu \mathrm{mol}$ of free fatty acid per minute under assay conditions.

The effects of $\mathrm{pH}$ and temperature on the activities of the free and immobilized lipase were investigated by incubating $0.1 \mathrm{~g}$ of MNp-Col-IL or $0.5 \mathrm{~mL}$ of free lipase $(50 \mathrm{mg} / \mathrm{mL})$ in the presence of $2 \mathrm{~mL}$ of buffer for one hour under different $\mathrm{pH}$ and temperature conditions. The activity of the free and immobilized lipase was determined a temperature range of $15-70{ }^{\circ} \mathrm{C}$ and at a $\mathrm{pH}$ range of 4.0-10.0 buffered by $50 \mathrm{mM}$ sodium phosphate at $\mathrm{pH} 4.0-6.5,50 \mathrm{mM}$ Tris- $\mathrm{HCl}$ at $\mathrm{pH} 7.0-9.0,50 \mathrm{mM}$ $\mathrm{Na}_{2} \mathrm{CO}_{3}-\mathrm{NaHCO}_{3}$ at $\mathrm{pH} 9.5-10$. All the experiments for catalytic activity test are measured in triplicate.

\subsection{Characterizations of MNp-Col Supports and Immobilized Lipase}

The SEM micropraphs were obtained on a JSM 7500F scanning electron microscope (JEOL, Tokyo, Japan). $\mathrm{N}_{2}$ adsorption-desorption isotherms and pore size distributions were obtained on a Micromeritics Tristar 3000 system (Micromeritics, Norcross, GA, USA). The surface area was calculated by BET equation. The MNp-Col-IL dispersed in aqueous or olive oil was directly separated by an imposed magnetic field. DSC data of collagen fibers, Mnp-Col and MNp-Col-IL were measured on a 200DSC scanning calorimeter (NETZSCH, Selb, Germany) from $20-150{ }^{\circ} \mathrm{C}$ with a $5{ }^{\circ} \mathrm{C} / \mathrm{min}$ heating rate. The TG profiles of collagen fibers, $\mathrm{MNp}-\mathrm{Col}$ and $\mathrm{MNp}$-Col-IL were recorded on a NETZSCH 20 9 thermo gravimetric analyzer (NETZSCH, Selb, Germany) from $40-600{ }^{\circ} \mathrm{C}$ with a $10{ }^{\circ} \mathrm{C} / \mathrm{min}$ heating rate. All samples were run in triplicate.

\subsection{Determination of Storage Stability, and Reusability}

To evaluate their storage stabilities, free and immobilized lipases were stored in $50 \mathrm{mM}$ Tris- $\mathrm{HCl}$ buffer ( $\mathrm{pH}$ 8.0) at $4{ }^{\circ} \mathrm{C}$ for up to 30 days. The relative activity was defined as the ratio between the activity measured at a given time and the initial activity measured at the beginning of the incubation. The used biocatalyst was recovered from the reaction medium by an imposed magnetic field and washed with deionized water and PBS buffer. The lyophilized recovering MNp-Col-IL was introduced into a fresh medium for a next run up to 10 cycles.

\subsection{Kinetic Constants Determination}

The kinetic parameters of free lipase and MNp-Col-IL were obtained by using various initial concentrations of olive oil (15-100 mg/mL) as substrate at $40{ }^{\circ} \mathrm{C}$ and $\mathrm{pH} 8.0, K_{\mathrm{m}}$ and $V_{\max }$ were calculated by the Michaelis-Menten equation and the Lineweaver-Burk plots from the obtained data after reacting for $10 \mathrm{~min}$ :

$$
\frac{1}{V}=\left(\frac{K_{m}}{V_{\max }}\right) \frac{1}{S}+\frac{1}{V_{\max }}
$$

where $S$ is the substrate concentration $(\mathrm{mM}), V$ is the reaction velocity $(\mathrm{mM} / \mathrm{min}), V_{\max }$ is the apparent reaction velocity $(\mathrm{mM} / \mathrm{min})$, and $K_{\mathrm{m}}$ is the Michaelis-Menten constant $(\mathrm{mM})$. 


\subsection{Immobilized Lipase-Catalyzed Ester Synthesis}

The MNp-Col-IL prepared under optimal conditions was used for synthesis of butyrate by using various alcohols with the chain length from one (methanol) to six (n-hexyl alcohol). Briefly, butyric acid and alcohol at a 2:1 molar ratio was dispersed in hexane with the initial concentration of the alcohol at $0.1 \mathrm{M}$. After mixing well at $40{ }^{\circ} \mathrm{C}, 100 \mathrm{mg}$ of $\mathrm{MNp}$-Col-IL (water content, $2.0 \mathrm{uL} / \mathrm{mg}$ ) was added into $10 \mathrm{~mL}$ of the system with continuous shaking for $24 \mathrm{~h}$. To terminate the reaction, $5.0 \mathrm{~mL}$ of ethanol was added. The amount of the remaining acid in the system was titrated by $0.01 \mathrm{M}$ standard $\mathrm{NaOH}$ solution for calculating the yield of butyrate.

\section{Conclusions}

In this work, magnetic particles $\mathrm{Fe}_{3} \mathrm{O}_{4}$ were prepared by chemical coprecipitation and introduced into collagen fibers to form magnetic collagen support for enzyme immobilization. The prepared MNp-Col-IL displayed good magnetic separation abilities in both aqueous and organic media. $\mathrm{MNp}$-Col-IL presents a remarkable enhancement to the tolerance of temperature and $\mathrm{pH}$ variations in hydrolysis of olive oil emulsion. It was found that MNp-Col-IL showed effective catalyzing reaction for synthesis of butyrate esters with different chain length of alcohols, among which butyl butyrate was the highest yield. MNp-Col-IL maintains a high activity and specificity for butyrate synthesis in an n-hexane medium.

Acknowledgments: The authors are grateful for the financial provided by the National High Technology Research and Development Program of China [grant number 2013AA06A306], and the Key Research Program of Sichuan Province of China (2017GZ0268, 2017TD0010).

Author Contributions: H.C., S.H. and D.S. conceived and designed the experiments; S.H. and D.S. performed the experiments; D.S., M.C., and H. C. analyzed the data; H.C. wrote the paper.

Conflicts of Interest: The authors declare no conflict of interest.

\section{References}

1. Tibrewal, N.; Tang, Y. Biocatalysts for natural product biosynthesis. Annu. Rev. Chem. Biomol. Eng. 2014, 5, 5347-5366. [CrossRef] [PubMed]

2. Rodrigues, R.C.; Ortiz, C.; Berenguer-Murcia, A.; Torres, R.; Fernandez-Lafuente, R. Modifying enzyme activity and selectivity by immobilization. Chem. Sov. Rev. 2013, 42, 6290-6307. [CrossRef] [PubMed]

3. Reetz, M.T. Biocatalysis in organic chemistry and biotechnology: Past, present, and future. J. Am. Chem. Soc. 2013, 135, 12480-12496. [CrossRef] [PubMed]

4. Sheldon, R.A.; Sander, V.P. Enzyme immobilisation in biocatalysis: Why, what and how. Chem. Soc. Rev. 2013, 42, 6223-6235. [CrossRef] [PubMed]

5. Robert, D.C.; Joseph, M.A.; Poulose, A.J. Industrial use of immobilized enzymes. Chem. Soc. Rev. 2013, 42, 6437-6474.

6. Gupta, R.; Gupta, N.; Rathi, P. Bacterial lipases: An overview of production, purification and biochemical properties. Appl. Microbiol. Biotechnol. 2004, 64, 763-781. [CrossRef] [PubMed]

7. Martins, A.B.; Silva, A.M.; Schein, M.F.; Garcia-Galan, C. Comparison of the performance of commercial immobilized lipases in the synthesis of different flavor esters. J. Mol. Catal. B Enzym. 2014, 105, 18-25. [CrossRef]

8. Yassin, A.; Mohamed, I.; Ibrahim, M.; Yousoff, M. Effect of enzymatic interesterification on melting point of palm olein. Appl. Biochem. Biotechnol. 2003, 110, 45-52. [CrossRef]

9. Minovska, V.; Winkelhausen, E.; Kuzmanove, S. Lipase immobilized by different techniques on various support materials applied in oil hydrolysis. J. Serb. Chem. Soc. 2005, 70, 609-624. [CrossRef]

10. Fernandez-Lafuente, R. Lipase from thermomyces lanuginosus: Uses and prospects as an industrial biocatalyst. J. Mol. Catal. : Enzym. 2010, 62, 197-212. [CrossRef]

11. Mendes, A.A.; Freitas, L.; Carvalhoak, A.K.; Oliveira, P.C.; Castro, H.F. Immobilization of a commercial lipase from Penicillium camembertii (Lipase G) by different strategies. Enzyme Res. 2011, 40, 611-618. 
12. Santos, J.C.S.D.; Barbosa, O.; Ortiz, C.; Berenguer-Murcia, A.; Rodrigues, R.C.; Fernandez-Lafuente, R. Importance of the support properties for immobilization or purification of enzymes. ChemCatChem 2015, 7, 2413-2432. [CrossRef]

13. Ziegler-Borowska, M.; Chelminiak-Dudkiewicz, D.; Siódmiak, T.; Sikora, A.; Wegrzynowska-Drzymalska, D.; Skopinska-Wisniewska, J.; Kaczmarek, H.; Marszałł, M.P. Chitosan-collagen coated magnetic nanoparticles for lipase immobilization-New type of "enzyme friendly" polymer shell crosslinking with squaric acid. Catalysts 2017, 7, 26. [CrossRef]

14. Chen, S.; Song, N.; Liao, X.P.; Shi, B. Immobilization of catalase on Fe(III) modified collagen fiber. Chin. J. Biotechnol. 2011, 27, 1076-1081.

15. Song, D.W.; Chen, M.; Cheng, H.M. Collagen-immobilized lipases show good activity and reusability for butyl butyrate synthesis. Appl. Biochem. Biotechnol. 2016, 180, 826-840.

16. Jain, M.; Sebatini, A.M.; Radha, P. Synthesis, characterization and kinetic analysis of chitosan coated magnetic nanobiocatalyst and its application on glucose oleate ester synthesis. J. Mol. Catal. B Enzym. 2016, 128, 1-9. [CrossRef]

17. Motevalizadeh, S.F.; Khoobi, M.; Sadighi, A. Lipase immobilization onto polyethylenimine coated magnetic nanoparticles assisted by divalent metal chelated ions. J. Mol. Catal. B Enzym. 2015, 120, 75-83. [CrossRef]

18. Yue, W.; Wang, Y.; Luo, G. In situ preparation of magnetic $\mathrm{Fe}_{3} \mathrm{O}_{4}$-chitosan nanoparticles for lipase immobilization by cross-linking and oxidation in aqueous solution. Bioresour. Technol. 2009, 100, 3459-3464.

19. Zdarta, J.; Klapiszewski, L.; Jedrzak, A.; Nowicki, M.; Moszynski, D.; Jesionowski, T. Lipase B from Candida antarctica immobilized on a silica-lignin matrix as a stable and reusable biocatalytic system. Catalysts 2017, 7, 14. [CrossRef]

20. Huang, X.J.; Chen, P.C.; Huang, F.; Ou, Y.; Chen, M.R.; Xu, Z.K. Immobilization of Candida rugosa lipase on electrospun cellulose nanofiber membrane. J. Mol. Catal. B Enzym. 2011, 70, 95-100. [CrossRef]

21. Yu, W.H.; Tong, D.S.; Fang, M.; Shao, P.; Zhou, C.H. Immobilization of Candida rugosa lipase on MSU-H type mesopours silica for selective esterifiction of conjugated linoleic acid isomers with ethanol. J. Mol. Catal. B Enzym. 2015, 111, 43-50. [CrossRef]

22. Barbosa, O.; Torres, R.; Ortiz, C.; Fernandez-Lafuente, R. Versatility of glutaraldehyde to immobilize lipases: Effect of the immobilization protocol on the properties of lipase B from Candida antarctica. Process Biochem. 2012, 471, 1220-1227. [CrossRef]

23. Walt, D.R.; Agayn, V.I. The chemistry of enzyme and protein immobilization with glutaraldehyde. Trend Anal. Chem. 1994, 13, 425-430. [CrossRef]

24. Cunha, A.G.; Besteti, M.D.; Manoel, E.A.; Silva, A.; Freire, D. Preparation of core-shell polymer supports to immobilize lipase B from Candida antarctica: Effect of the support nature on catalytic properties. J. Mol. Catal. B: Enzym. 2014, 100, 59-67. [CrossRef]

25. Hilal, N.; Kochkodan, V.; Nigmatullin, R. Lipase-immobilized biocatalytic membranes for enzymatic esterification: Comparison of various approaches to membrane preparation. J. Membrane Sci. 2006, 268, 198-207. [CrossRef]

26. Chang, M.Y.; Juang, R.S. Activities, stabilities and reaction, kinetics of three free and chitosan-clay composite immobilized enzyme. Enzyme Microb. Technol. 2005, 36, 75-82. [CrossRef]

27. Frenkel-Mullerad, H.; Avnir, D. Sol-Gel materials as efficient enzyme protectors: Preserving the activity of phosphatases under extreme pH conditions. J. Am. Chem. Soc. 2005, 127, 8077-8081. [CrossRef] [PubMed]

28. Xie, W.L.; Wang, J.L. Enzymatic production of biodiesel from soybean oil by using immobilized lipase on Fe3O4/Poly (styrene-methacrylic acid) magnetic microsphere as a biocatalyst. Energy Fuels 2014, 28, 2624-2631. [CrossRef]

29. Tuzmen, N.; Kalburcu, T.; Denizli, A. Immobilization of catalase via adsorption onto metal-chelated affinity cryogels. Process Biochem. 2012, 47, 26-33. [CrossRef]

30. Sun, H.; Yang, H.; Huang, W.; Zhang, S. Immobilization of laccase in a sponge-like hydrogel for enhanced durability in enzymatic degradation of dye pollutants. J. Colloid Interface Sci. 2015, 450, 353-360. [CrossRef] [PubMed]

31. Deng, M.; Zhao, H.; Zhang, S.; Tian, C.; Di, Z.; Du, P. High catalytic activity of immobilized laccase on core-shell magnetic nanoparticles by dopamine self-polymerization. J. Mol. Catal. B Enzym. 2015, 112, 15-24. [CrossRef] 
32. Yahya, A.R.M.W.; Anderson, A.; Moo-Young, M. Ester synthesis in lipase-catalyzed reactions. Enzyme Microb. Technol. 1998, 23, 438-450. [CrossRef]

33. Chulalaksananukul, W.; Condoret, J.S.; Combes, D. Geranyl acetate synthesis by lipase-catalyzed transesterification in supercritical carbon dioxide. Enzyme Microb. Technol. 1993, 15, 691-698. [CrossRef]

34. Manjon, A.; Iborra, J.L.; Arocas, A. Short-chain flavor ester synthesis by immobilized lipase in organic media. Biotechnol. Lett. 1991, 13, 339-344. [CrossRef]

35. Bezbradica, D.; Karalazjc, I.; Ognjanovic, N.; Mijin, D.; Siler-Marikovic, S.; Knezevic, Z. Studies on the specificity of Candida rugosa lipase catalyzed esterification reactions in organic media. J. Serb. Chem. Soc. 2006, 71, 31-41. [CrossRef]

36. De Barros, D.P.C.; Lemos, F.; Fonseca, L.P.; Cabral, J.M.S. Kinetic cutinase-catalyzed esterification of caproic acid in organic solvent system. J. Mol. Catal. B Enzym. 2010, 66, 285-293. [CrossRef]

37. Kumar, R.; Modak, J.; Madras, G. Effect of chain length of the acid on the enzymatic synthesis of flavors in supercritical carbon dioxide. Biochem. Eng. J. 2005, 23, 199-202. [CrossRef]

38. Martins, A.; Friedrich, J.; Cavalheiro, J.; Garcia-Galan, C.; Barbosa, O.; Ayub, M.; Fernandez-Lafuente, R.; Rodrigues, R. Improved production of butyl butyrate with lipase from Thermomyces lanuginosus immobilized on styrene-divinylbenzene beads. Bioresour. Technol. 2013, 134, 417-422.

39. Lai, D.T.; O'Connor, C.J. Studies on synthesis of short chain alkyl esters catalyzed by goat pregastric lipase. J. Mol. Catal. B Enzym. 1999, 6, 411-420. [CrossRef]

40. Langrand, G.; Rondot, N.; Triantaphylides, C.; Baratti, J. Short-chain flavour esters synthesis by microbial lipases. Biotechnol. Lett. 1990, 12, 581-586. [CrossRef]

41. Gandhi, N.N.; Sawant, S.B.; Joshi, J.B. Specificity of a lipase in ester synthesis: Effect of alcohol. Biotechnol. Progr. 1995, 11, 282-287. [CrossRef]

42. Cheng, H.M.; Chen, M.; Liao, L.L.; Li, Z.Q. Chemical and physical behavior of collagen fiber in alkaline solutions. J. Sci. Leather Technol. Chem. 2009, 93, 140-144.

43. Hou, A.J.; Xu, B.B.; Liang, L.; Li, Y.H.; Peng, B.Y. A modified colorimetric assay of lipase activity using emulsified olive oil as the substrate. Leather Sci. Eng. 2011, 21, 22-27.

(C) 2017 by the authors. Licensee MDPI, Basel, Switzerland. This article is an open access article distributed under the terms and conditions of the Creative Commons Attribution (CC BY) license (http:/ / creativecommons.org/licenses/by/4.0/). 